\title{
WeChat Users' Information Protection Behavior Based on Prospect Theory
}

\author{
Yueshu Zhao and Mingsheng Zhao
}

\begin{abstract}
In network environment, information users' role and position have changed greatly, and users' experience and perception during information interaction will influence their assessment of information quality and their satisfaction. This paper tests and corrects the information quality influencing factors model from network user experience and perception view which putted forward based on previous research results with questionnaire survey research methods. The results show that the model is consisted of six dimensions, such as information features, help and support, sensory psychological, service procedure, basic function user personality literacy. The indexes of the model covers the information quality influencing factors which network user experienced and perceived from all-dimensional view during information interaction and acquisition process. It also embodies and reflects the basic characters and practical demands of network users. Research results will provide reference path which could promote information quality through optimizing user information experience and perception.
\end{abstract}

Index Terms-WeChat, uses' information protection behavior, structural equation modeling, prospect theory.

\section{INTRODUCTION}

In the four years since its launch, WeChat has become the world's most widely used mobile-time messaging application. Users can quickly send texts, voices, pictures, videos and other content through the mobile phone almost freely. This information is published anywhere, anytime, with different contents. One of the important parts is the behavior of user information releasing. Social media encourages users to post information in real-name or anonymous ways and establish a circle of friends.

In this context, multi-dimensional self-exhibition and even the re-shaping of self-image on the Internet has become a major theme of WeChat. Users actively post information through WeChat. This information release is affected by various factors such as the external environment and internal character. The study of such influencing factors is the premise for the study of various aspects of the WeChat user information release such as psychology and motivation, which has important theoretical significance. Finding out the influencing factors that restrict the efficiency of user information release can enhance WeChat's practical value of providing information, obtaining information, and efficiently

Manuscript received October 18, 2018; revised April 15, 2019. This work was supported in part by Top-notch Academic Programs Project of Jiangsu Higher Education Institutions under Grant PPZY2015A058 and Special Funds for Fundamental Research Business Fees in Central Universities under Grant LGYB201716.

The authors are with the Nanjing Forest Police College, Nanjing, 210023, China (e-mail: zysqq83@163.com,njzms@163.com). utilizing information by enhancing people's ability to interpret and use WeChat user information.

In the existing WeChat research, there is less research on the behavior of user information release. Based on the technology acceptance model, combining the structural equation model and data analysis, this paper classifies the user's demographic information, proposes a model of the influencing factors of the behavioral intention of the user information release. Through the analysis of the influencing factors and the mutual relations, we can find ways to improve the efficiency of WeChat user information release.

\section{RELATED WoRKS AND RESEARCH MODEL}

\section{A. Studies on the Social Media's Self-disclosure}

Self-disclosure comes from psychology, which is the window of the individual's expression of emotions, ideas, and opinions to others [1]. Self-disclosure is a kind of behavior that people voluntarily and intentionally tell others about their own real situations [2]. In the network environment, people can provide detailed personal information, express their views and opinions at any time and anywhere. The opportunities for self-disclosure are increased, and the attention of others may be increased. At present, there are many researches based on self-disclosure in China, mostly focusing on psychological and educational research. Research on the Internet has also risen, and self-disclosure has been involved in social media research, but little research has been done. The intention of users to publish information related to themselves may be related to the degree of self-disclosure. Factors that affect self-disclosure may also affect the user's intention to publish information.

The study of self-disclosure in social media has emerged, in which the role of self-disclosure in interpersonal communication and the influencing factors of self-disclosure is the main research. Peng Juan took SNS users as research objects, and studied the self-disclosure features of SNS users in different topics, different target persons, and different purposes of use, and analyzed the reasons. Considering impact of interpersonal transmission on individuals, the self-disclosure of SNS users has made the grassroots become opinion leaders and promoted individuals to form online communities; In terms of human relationships, self-disclosure causes the original group sites to be destroyed, and reshapes users' new group identity; In the development of interpersonal relationships, self-disclosure promotes the development of network interpersonal relationships and complements real interpersonal relationships. There are relatively many domestic researches on the factors affecting 
self-disclosure of users in social media. The influencing factors include motivation, trust, risk perception, privacy concerns, cyberspace cognition, functionality and so on. Jaafar and Ariffin divides motivation into information and tool motivation[3], entertainment and aesthetic motivation, social motivation, altruism motivation, sense of belonging and identity motivation, and internalization motivation. These motivations will have an impact on the user's time of use, frequency of use, and level of use. In different levels of trust, motivations will influence use behavior with different ways and degrees.

\section{B. The Development and Application of Prospect Theory}

Technology acceptance model is one of the theories that have a significant impact on the user's acceptance of information technology. It is mainly used to study the influencing factors of users when adopting new technologies.

Davis proposed technology acceptance model based on rational behavior theory, planned behavior theory, self-efficacy theory, input-output theory, change adoption theory, and expectation theory model to study the acceptance and adoption of information technology [4].

In 2003, Venkatesh proposed a unified technology acceptance and use model, based on theory of reasoned action, technology acceptance model, motivational model, theory of planned behavior, combined TAM and TPB model, model of PC utilization, innovation diffusion theory, and social cognitive theory total eight models. The model increases the ability to explain behavioral intentions to $70 \%$. Among them, behavioral intentions are directly affected by three factors: performance expectations, effort expectations, and social influence. Gender, age, experience, and willingness have a modulating effect. Performance expectation refers to the degree to which users believe that the use of new technology will improve the performance of their work. Effort expectation refers to the ease of users using the new technology. Social influence is the degree to people that users think they are important think they should use the new technology.

After continuous development of the technology acceptance model, it has been increasingly applied to the research under the network environment. The research on the use behavior of social media users is also involved. Some scholars have added three elements in ATM: the perception of matching degree, trust, and perceived pleasure, and studied the influence factors of consumer shopping attitudes of social networking sites shopping [5]. Some literature added the modulating variables such as perceived risk, perceived low price, positive word-of-mouth influence and demographic variables to study the influencing factors of consumers' willingness in online group purchase [6]. In the study of micro-blog, scholars added trust and perceived risk to build an acceptance model of micro-blog user. However, the analysis results suggest that these two factors have no significant effect on the user's willingness to use [7]. Researchers explored the motivation and behavior of micro-blog users by uniting technology acceptance model with the theory of uses and gratifications [8], studied the influence factors of SNS users' acceptance via combining with the technology acceptance model and user satisfaction theory, and verified that these three factors will affect perceived usefulness and perceived ease of use by adding the system quality, information quality and service quality extracted from user satisfaction theory, and then affect the behavioral intention of the user. It's also a current research direction that combine technology acceptance model with task-technology fit model (TTF) to study the utilization of user network information [9].

Based on the technology acceptance model, this paper adds variables, such as trust, control, risk perception, profit perception and so on, to analyze the basic usage behavior of WeChat users, identify the influencing factors that affect the behavioral intention of WeChat users, and distinguish the behavior preference of information publishing among different groups of WeChat users.

As shown in Figure 1, the left part of the model is independent variables, which are trust, information control, perceived risk, purposes of network behavior, and practicality. The right part of the model is personal information disclosure and the behavioral intention of information release of WeChat users. In many cases, the information release of WeChat users is to introduce themselves and express their own opinions, which is related to the disclosure of the user's personal information.

The dependent variable is "behavioral intention of information release" rather than "user behavior", because a large number of studies have proved that behavioral intention has a significant causal relationship with actual use behavior and is a direct determinant. Although the research abandoned the behavioral intention, a link of use behavior, the model can well explain the user's behavior of information release by the behavioral intention.

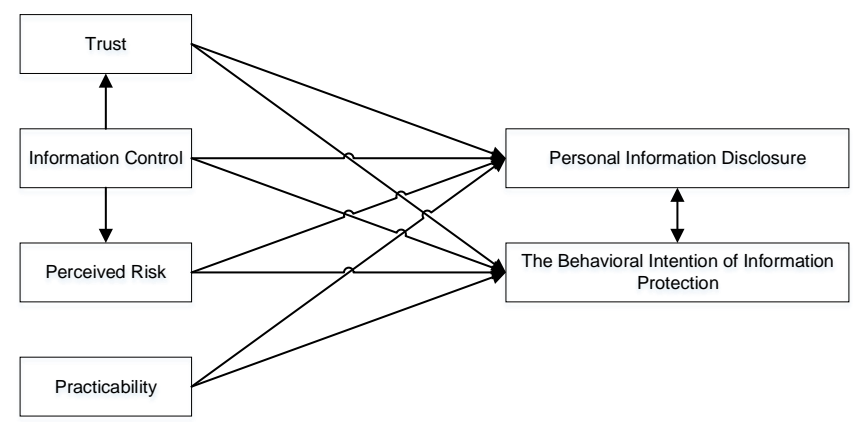

Fig. 1. Conceptual model of the study.

\section{VARIABLE DEFINITIONS AND RESEARCH HyPOTHESES}

\section{A. The Definition of Trust and Hypotheses}

In this study, trust refers to the user's trust in WeChat when they publish information. In the study of the influencing factors of self-disclosure by Hanna Krasnova et al., the research based on the study of McKnight summarized the scale of trust in media platform, and the research based on Chiu et al. summarized the scale of trust to other users. This paper borrows Hanna Krasnova's classification and definition of trust, adopts the scale of measuring the trust to the platform and the user. And it divides the user's trust in WeChat when they publish information into two parts: Firstly, the trust in WeChat platform; Secondly, the trust in other users in WeChat. The study on SNS by Dwyer, Hiltz, and 
Passerini [10], Mietzner and Lin [11] and others suggest that users' trust can reduce the perception of privacy risks, and Steel believes that trust can increase the depth of self-disclosure [12].

Previous research on the relationship between trust and self-disclosure confirmed that trust has a positive effect on self-disclosure. The study proposes the following hypotheses:

H1-1: Trust has no effect on personal information disclosure of WeChat users;

H1-2: Trust has no effect on the user's behavioral intention of information release;

H1-3: Trust has no effect on perceived risk of WeChat users.

\section{B. The Definition of Information Control and Hypotheses}

Information control refers to the user's perception of the degree of personal information control. Altman (1976) proposed that "information control is the center of privacy", which shows that personal sense of control over their information is an important factor that influences self-disclosure [13]. Dianne and Carolyn (2008) [14], Joshua and Elham (2009) [15], and Skinner (1996) believe that when SNS users lack confidence in controlling information, they tend to reduce personal disclosure due to attention to risk [16]. Gefen (2000) [17], Willmott, Knights, Noble and Vurdubabis (2001) [18], and Oliver (2000) [19] believe that the increase of the sense of trust can enhance users' perceptions of information control. However, this study believes that in the use of WeChat, users control the information they post through the function of WeChat settings. The increased sense of control allows users to trust the WeChat platform and other users more and more. Based on this, this study proposes the following hypotheses:

H2-1: The information control of WeChat users has no effect on their trust;

H2-2: Information Control has no effect on personal information disclosure;

H2-3: The information control of WeChat users has no effect on risk perception.

H2-4: The information control of WeChat users has no effect on the behavior of information release.

\section{The Definition of Perceived Risk and Hypotheses}

Perceived risk refers to the perception of the leakage of personal information when users submit personal information and exchange information. Perceived risk is widely applied to the research on consumer behavior, while they may feel privacy risks in the behavior of information release of WeChat users, thereby users will reduce personal information disclosure and the behavior of information release which related to personal information. This study proposes the following hypotheses:

H3-1: Perceived risk negatively affect personal information disclosure;

H3-2: Perceived risks directly affect the user's behavior intention of information release and have different degrees of influence on different types of information release intention.

D. The Definition of Personal Information Disclosure and Hypotheses
Personal information disclosure refers to the degree of personal information disclosure by WeChat users. Users' self-disclosure in WeChat can be divided into three parts: a. the description related to personal life; $b$. the display and expression of personal opinions; $c$. the introduction of basic personal information. The former two are dynamic information release, which can be measured by the intention of information release, while the latter one is relatively stable personal introduction, which can be measured by using the degree of personal information disclosure. This paper uses the personal information disclosure scale used by Hanna Krasnova in a self-developed study to measure the degree of personal information disclosure of WeChat users.

Research have shown that the abundance of emotional expression in virtual community will play a positive role in information release. This study believes that the personal information disclosure may be related to the behavioral intention of information release, and whether it is causality or not needs to be verified. The following hypotheses are proposed:

H4: Personal information disclosure is related to certain aspects of the behavioral intention of information release.

\section{E. The Behavioral Intention of Information Release}

Behavioral intention of information release is user's intention when they post information.

Jeffrey T. Child et al. studied the changes in the privacy management of blog users during different stages of social media use. In the study, blog users were divided into self-centered, utilitarian, planned, shared, self-protected, and calming total six types. This study has introduced its user classification scale to measure WeChat users. Due to differences in media platforms and countries, the scale will be arranged to adapt to WeChat user classification.

\section{DAta Collection And Model Validation}

\section{A. Data Collection}

In this study, questionnaires were used to collect data. The questionnaire included six variables of the measurement model: trust, information control, perceived risk, practicality, personal information disclosure, and the behavioral intention of information release. We learn from existing maturity scales in domestic and foreign research, combine the features of WeChat and Chinese semantic environment to modify and adjust, modify or delete unclear items, and form a questionnaire with high reliability and validity.

The research relies on "Research Project on Social Media Users Behavior Models and Management Mechanisms", and distributed questionnaires nationwide through professional survey companies, covering different categories based on gender, age, region, occupation, education level, income, etc. A total of 3000 valid questionnaires were collected by online questionnaires. We selected users who primarily logs in and uses WeChat in the use of social media. A total of 1,416 samples were obtained. And the following research will be based on these 1,416 samples.

\section{B. Model Validation}


We construct a structural equation model based on the conceptual model, use AMOS to analyze each path in the model hypotheses, and delete a total of 12 insignificant paths based on the results.

At this point, from the model fitting index (Table I), the final structural equation model fits well and is superior to the original model. All paths are significant, and the critical ratio values meet the requirements, which shows that all paths of the final structural equation model are established.

TABLE I: THE FitTING INDEX OF FinAL STRUCTURAL EQUATION MODEL

\begin{tabular}{lccccccc}
\hline \multicolumn{1}{l}{ Absolute Fitting Index } & & \multicolumn{5}{c}{ Value-added Fitting Index } \\
\hline $\begin{array}{l}\text { Chi-square/ } \\
\text { Free degree }\end{array}$ & GFI & RMR & RMSEA & AGFI & NFI & CFI & IFI \\
3.41 & 0.91 & 0.04 & 0.04 & 0.90 & 0.88 & 0.91 & 0.91 \\
\hline
\end{tabular}

According to the final result of the structural equation model, the hypothesis proposed at the beginning of this paper is verified and the results are as follows.

TABLE II: HYPOTHESIS TESTING RESUlTS OF CONCEPTUAL MODEL

\begin{tabular}{ll}
\hline \hline Hypotheses of Conceptual Model & Hypothesis Testing Results \\
\hline Hal & Acceptance \\
H1-1 & Acceptance, positive influence \\
H1-2 & Reject \\
H1-3 & Reject, negative effect \\
H2-1 & Reject, positive effect \\
H2-2 & Acceptance \\
H2-3 & Acceptance \\
H2-4 & Reject \\
H3-1 & Acceptance \\
H3-2 & Reject \\
H4 & Reject
\end{tabular}

Note: Not completely established that the independent variable has some influence on some aspects of the dependent variable but has no effect on others.

The structural equation model is relatively weak in analyzing different groups, while multiple linear regression equations can well explore the influence of different groups on the dependent variables. Therefore, we try to construct multiple linear regression equations to further explore the relationship between demographic variables and the behavioral intention of user information release.

According to the results of factor analysis of behavioral intention of information release, four kinds of information release intention are calculated to obtain scores of various intention. The higher the score is, the higher the degree of such intention is, which is regarded as dependent variable. The demographic variables, online duration, and internet age were chosen as independent variables to construct a multiple linear regression equation to further explore the relationship between demographic variables and the behavioral intention of WeChat user's information release. The construction of multivariate regression equation is shown in Table III. This paper only lists the data of users who belong to the type of "open expression of views" and "discreet information release".

TABLE III: MULTIPLE LINEAR REGRESSION EQUATION OF USERS' INFORMATION RELEASE TYPE

\begin{tabular}{|c|c|c|c|c|}
\hline \multirow[b]{2}{*}{ Variable } & \multicolumn{2}{|c|}{$\begin{array}{l}\text { Open } \\
\text { expression } \\
\text { of views }\end{array}$} & \multicolumn{2}{|c|}{$\begin{array}{l}\text { Discreet } \\
\text { information } \\
\text { release }\end{array}$} \\
\hline & $\mathrm{B}$ & Sig- & $\mathrm{B}$ & Sig- \\
\hline Constant & $\begin{array}{l}9.31 \\
5\end{array}$ & $\begin{array}{l}0.1 \\
07\end{array}$ & $\begin{array}{l}20 . \\
166\end{array}$ & $\begin{array}{l}0.00 \\
0\end{array}$ \\
\hline Male & 0.04 & $\begin{array}{l}0.6 \\
89\end{array}$ & $\begin{array}{l}-0.0 \\
48\end{array}$ & $\begin{array}{l}0.25 \\
1\end{array}$ \\
\hline Non-system outside & $\begin{array}{l}-0.02 \\
5\end{array}$ & $\begin{array}{l}0.6 \\
68\end{array}$ & $\begin{array}{l}-0.0 \\
3\end{array}$ & $\begin{array}{l}0.71 \\
8\end{array}$ \\
\hline Unmarried & $\begin{array}{l}-0.08 \\
2\end{array}$ & $\begin{array}{l}0.2 \\
89\end{array}$ & $\begin{array}{l}-0.0 \\
36\end{array}$ & $\begin{array}{l}0.57 \\
9\end{array}$ \\
\hline Square root of age & $\begin{array}{l}-0.68 \\
8\end{array}$ & $\begin{array}{l}0.3 \\
38\end{array}$ & & \\
\hline Fourth power root of age & $\begin{array}{l}2.63 \\
7\end{array}$ & $\begin{array}{l}0.4 \\
51\end{array}$ & $\begin{array}{l}-0.5 \\
43\end{array}$ & $\begin{array}{l}0.20 \\
6\end{array}$ \\
\hline $\begin{array}{l}\text { Unmarried*Non-system } \\
\text { outside*Male*Square root of age }\end{array}$ & $\begin{array}{l}-1.15 \\
7\end{array}$ & $\begin{array}{l}0.0 \\
00\end{array}$ & $\begin{array}{l}0.9 \\
05\end{array}$ & 0.01 \\
\hline $\begin{array}{l}\text { Unmarried*Non-system } \\
\text { outside*Male*Fourth power root of } \\
\text { age }\end{array}$ & $\begin{array}{l}2.54 \\
7\end{array}$ & $\begin{array}{l}0.0 \\
00\end{array}$ & $\begin{array}{l}-2.4 \\
79\end{array}$ & $\begin{array}{l}0.00 \\
2\end{array}$ \\
\hline $\begin{array}{l}\text { Not unmarried*System } \\
\text { outside*Male*Square root of education } \\
\text { level }\end{array}$ & & & $\begin{array}{l}1.4 \\
2\end{array}$ & $\begin{array}{l}0.00 \\
7\end{array}$ \\
\hline $\begin{array}{l}\text { Not unmarried*System } \\
\text { outside*Male*Fourth power root of } \\
\text { education level }\end{array}$ & & & $\begin{array}{l}-2.0 \\
29\end{array}$ & $\begin{array}{l}0.01 \\
1\end{array}$ \\
\hline Square root of education level & $\begin{array}{l}4.42 \\
4\end{array}$ & $\begin{array}{l}0.0 \\
56\end{array}$ & $\begin{array}{l}2.9 \\
15\end{array}$ & $\begin{array}{l}0.12 \\
4\end{array}$ \\
\hline Fourth power root of education level & $\begin{array}{l}-12.2 \\
17\end{array}$ & $\begin{array}{l}0.0 \\
62\end{array}$ & $\begin{array}{l}-7.7 \\
96\end{array}$ & $\begin{array}{l}0.14 \\
7\end{array}$ \\
\hline $\begin{array}{l}\text { Not unmarried*Non-system } \\
\text { outside*Male*Square root of education } \\
\text { level }\end{array}$ & $\begin{array}{l}-1.15 \\
2\end{array}$ & $\begin{array}{l}0.0 \\
61\end{array}$ & $\begin{array}{l}1.4 \\
2\end{array}$ & $\begin{array}{l}0.00 \\
7\end{array}$ \\
\hline $\begin{array}{l}\text { Not unmarried*Non-system } \\
\text { outside*Male*Fourth power root of } \\
\text { education level }\end{array}$ & $\begin{array}{l}1.65 \\
8\end{array}$ & $\begin{array}{l}0.0 \\
71\end{array}$ & $\begin{array}{l}-2.0 \\
29\end{array}$ & $\begin{array}{l}0.01 \\
1\end{array}$ \\
\hline Square of income & $\begin{array}{l}0.00 \\
5\end{array}$ & $\begin{array}{l}0.3 \\
86\end{array}$ & $\begin{array}{l}2.0 \\
61\end{array}$ & $\begin{array}{l}0.00 \\
3\end{array}$ \\
\hline Cube of income & $\begin{array}{l}0.00 \\
0\end{array}$ & $\begin{array}{l}0.9 \\
36\end{array}$ & $\begin{array}{l}-3.0 \\
74\end{array}$ & $\begin{array}{l}0.00 \\
1\end{array}$ \\
\hline $\begin{array}{l}\text { Not unmarried*Male*Square of } \\
\text { income }\end{array}$ & -0.03 & $\begin{array}{l}0.0 \\
34\end{array}$ & & \\
\hline Not unmarried*Male*Cube of income & $\begin{array}{l}0.00 \\
2\end{array}$ & $\begin{array}{l}0.0 \\
4\end{array}$ & & \\
\hline Reciprocal of online duration & $\begin{array}{l}-0.56 \\
5\end{array}$ & $\begin{array}{l}0.3 \\
04\end{array}$ & $\begin{array}{l}-0.5 \\
43\end{array}$ & $\begin{array}{l}0.20 \\
6\end{array}$ \\
\hline $\begin{array}{l}\text { Reciprocal of the square root of online } \\
\text { duration }\end{array}$ & $\begin{array}{l}0.30 \\
4\end{array}$ & $\begin{array}{l}0.6 \\
47\end{array}$ & $\begin{array}{l}0.3 \\
28\end{array}$ & $\begin{array}{l}0.51 \\
7\end{array}$ \\
\hline $\begin{array}{l}\text { Not unmarried*Male* Reciprocal of } \\
\text { online duration }\end{array}$ & $\begin{array}{l}-3.96 \\
1\end{array}$ & $\begin{array}{l}0.0 \\
01\end{array}$ & $\begin{array}{l}-1.4 \\
12\end{array}$ & $\begin{array}{l}0.01 \\
4\end{array}$ \\
\hline $\begin{array}{l}\text { Not unmarried*Male*Reciprocal of the } \\
\text { square root of online duration }\end{array}$ & $\begin{array}{l}3.48 \\
8\end{array}$ & $\begin{array}{l}0.0 \\
03\end{array}$ & $\begin{array}{l}0.8 \\
92\end{array}$ & $\begin{array}{l}0.03 \\
3\end{array}$ \\
\hline Network age & $\begin{array}{l}-0.02 \\
1\end{array}$ & $\begin{array}{l}0.0 \\
00\end{array}$ & $\begin{array}{l}-0.0 \\
76\end{array}$ & 0.02 \\
\hline
\end{tabular}

By constructing the structural equations model, the causality between trust, perceived risk, information control, practicality and behavioral intention of information release was verified. We verified the causality between trust, information control, practicality, and personal information disclosure. And we verified the causality between the behavioral intention of information release and personal information disclosure.

The effects of, internet age, and online duration on 
behavioral intention of information release were verified by constructing a multivariate linear regression equation. We obtained a modified model of behavioral intention of information release based on the results of structural equation model and multiple linear regression equations (Fig. 2).

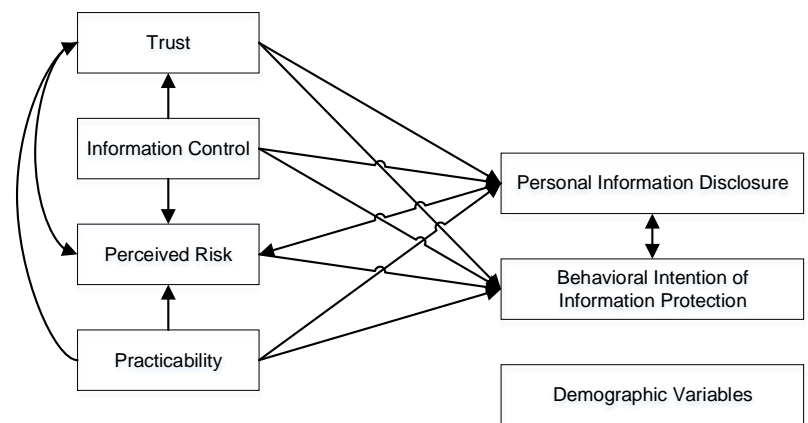

Fig. 2. A modified model for influencing factors of behavioral intention of information protect.

\section{Analysis of Results}

1) Information control increases user's trust while also increases the user's perceived risk, which will promote people to express their ideas. Information control is related to practicality. Practicality includes expanding their circle of friends through WeChat, showing that users with a strong sense of information control have a stronger sense of practicality in the use of WeChat. The increase of users' experience in WeChat will enhance their sense of control over the information they post.

2) Practicality will slightly affect the user's trust and perceived risk, and affect user's behavioral intention of information release. Some aspects of practicability have an impact on perceived risk. "Enhanced circle of friends" of practicability has no impact on the user's perceived risk. "Become a tool of communication" of practicability has a positive influence on perceived risk, but the influence is weak. It shows that the more WeChat users use WeChat as a communication tool, the more communication they use $\mathrm{WeChat}$, the greater the amount of information, and the higher the likelihood of being exposed to risk, and the stronger the risk perception of users. And the expansion of the circle of friends will not bring any changes in user risk perception.

3) The promotion of trust will greatly reduce the risk perception of users, promote the disclosure of user's personal information, and affect the user's behavioral intention of information release. With the increase of user's trust in WeChat, the risk perception of users will be greatly reduced. Improving the trust of the WeChat platform and other users will increase the security of personal information provided by users to the media platform, thereby reducing the risk perception of users to submit information. Improving the trust of the WeChat platform and other users will enhance the user's sense of security in the process of communication, thus reducing the risk perception of users in the process of information exchange.

4) Perceived risk will make the user's release behavior tend to be cautious and conservative, but it also stimulates users to generate the behavior of information release.
Perceived risk have no significant effect on the type of open information release. Such users are more open in posting information, and their perception of risk does not affect their decision to release information.

5) The disclosure of personal information may be affected by behavioral intention of information release. And the increase in the degree of personal information disclosure will increase the risk perception of users. Through the model test, the intention of the type of "open expression of views" has a positive impact on personal information disclosure, and the intention of the type "discreet information release" has a negative impact on individual information disclosure. The WeChat users who are open to information release have a higher degree of personal information disclosure at WeChat.

6) Demographic variables have a significant impact on users' behavior of information release. By constructing multiple linear regression equations, it is found that gender, marital status, occupation, age, income, education level, network age, and duration of online use have a significant impact on the behavioral intention of information release. Age and income have a positive impact on users' intention to publish information. With the increase of age, users prefer to express their opinions. And with the increase of income, the degree of intention of all kinds of information release has been strengthened. In terms of educational background, the information release intention of low-educated and high-educated groups are higher than other groups. The influence of educational background on the intention of information release is U-shaped. The network age has a negative effect on the intention of users' information release, and the degree of intention of users' information release will decline with the increase of the network age, but the range is very small.

\section{CONCLUSION AND DISCUSSION}

At the beginning of this paper, two problems to be solved are proposed: whether the factors proposed by the self-disclosure theory can be well combined with the original factors of the technology acceptance theory, and whether the relationship between the factors can be verified under the new model framework. After empirical examination of the data, the following conclusions are as follows:

1) Perceived usefulness can be better combined with other factors, such as perceived benefits, and has a significant impact on personal information disclosure and behavioral intention of information release, which indicates that the technology acceptance model is still applicable in the WeChat environment. Factors such as trust, perceived risk, information control, and practicality can be well combined with the technology acceptance model, which together have a significant impact on personal information disclosure and the behavioral intention of information release.

2) Under the new model framework, variables such as trust, perceived risk, information control, and personal information disclosure all play a role in impacting or being affected, and there is no phenomenon that 
variables can not adapt to the new model framework.

In terms of the introduction of demographic variables, this study can only explore the influence of demographic variables on the information release behavior by constructing regression equations outside the model, because AMOS is relatively weak in the comparison of group models. It is hoped that future research can find a better way to add demographic variables to the structural equation model to verify.

\section{REFERENCES}

[1] P. A. Norberg, D. R. Horne, and D. A. Horne, "The privacy paradox: personal information disclosure intentions versus behaviors," Journal of Consumer Affairs, vol. 41, no. 1, pp. 100-126, 2007.

[2] S. M. Jourard, "Self-disclosure: An experimental analysis of the transparent self," Revista Española De Cardiología, vol. 63, no. 12, pp. 1438-1443, 2005.

[3] N. I. Jaafar and M. Y. M. Ariffin, "Understanding users' motivation to continue using social networking sites(sns)," Jurnal Komunikasi Malaysian Journal of Communication, vol. 32, no. 2, pp. 590-605, 2016.

[4] D. F. Davis, "A technology acceptance model for empirically testing new end-user information systems: theory and results," Ph.D. dissertation, MIT Sloan School of Management, Cam-bridge, MA, 1986.

[5] L. Liang and X. Qin, "Research on consumers online shopping decision-making and recommendation of commodity based on social media network," Cluster Computing, pp. 1-11, 2018.

[6] Y. Pan, S. Chaipoopirutana, and H. Combs, "A study of the factors influencing online purchase intention of consumers in China," American Society of Business and Behavioral Sciences, vol. 6, no. 1, pp. $88-99,2010$

[7] W. Shu, Continual Use of Microblogs, Taylor \& Francis, Inc, 2014.

[8] L. Zhang and I. Pentina, "Motivations and usage patterns of Weibo," Cyberpsychology, Behavior, and Social Networking, vol. 15, no. 6, pp. 312-317, 2012.

[9] L. Ming, Y. Lei, and X. Li, "Research on the efficiency model and index frame for utilization of web information resource based on the integration of TAM and TTF," Journal of the China Society for Scientific \& Technical Information, vol. 28, no. 1, pp. 128-136, 2009.

[10] C. Dwyer, S. R. Hiltz, and K. Passerini, "Trust and privacy concern within social networking sites: A comparison of Facebook and Myspace," AMCIS Proceedings, pp. 339-350, 2007.

[11] S. Mietzner and L. W. Lin, "Would you do it again? Relationship skills gained in a long-distance relationship," College Student Journal, vol. 39 , no. 1, pp. 192-200, 2005.

[12] J. L. Steel, "Interpersonal correlates of trust and self-disclosure," Psychological Reports, vol. 68, pp. 1319-1320, 1991.

[13] I. Altman, "Privacy: A conceptual analysis," Environment and Behavior, vol. 8, no. 1, pp. 7-29, 1976.

[14] M. T. Dianne and J. D. Carolyn, "Privacy and social networking sites," New Directions for Student Services, no. 124, pp. 89-102, 2008.
[15] F. Joshua and N. Elham, "Internet social network communities: Risk taking, trust, and privacy concerns," Computer in Human Behavior, no. 25 , pp. $153-160,2009$.

[16] E. A. Skinner, "A guide to constructs of control," Journal of Personality \& Social Psychology, vol. 71, no. 3, pp. 549-570, 1996.

[17] D. Gefen, "E-commerce: The role of familiarity and trust," Omegat: The International Journal of Management Science, no. 28, pp. 725-737, 2000.

[18] H. Willmott, D. Knights, F. Noble, and T. Vurdubakis, "Chasing shadows: control, virtuality and the promotion of trust," Organization Studies, vol. 22, no. 2, pp. 311-336, 2001.

[19] N. Olivero, "Consumption in the electronic environments. Understanding new consumer's behavior," in Proc. XXV Annual Colloquium of the International Association for Research in Economic Psychology and SABE Conference, Baden, Austria, 12-16 July, 2000.

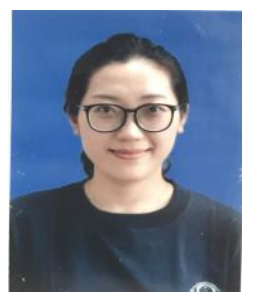

Yueshu Zhao is lecturer/master, teacher of Nanjing Forestry Police College. Her research interests are criminal technology. She published 6 academic papers, presiding over 3 projects of Central Universities and 1 project of provincial and ministerial level.

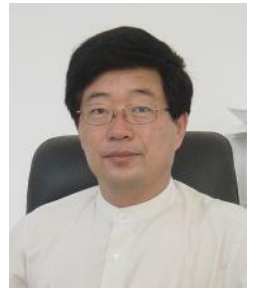

Mingsheng Zhao a second-level professor. He is an expert who enjoys special allowances from the state council, an expert in the evaluation of national science and technology awards, an expert in the construction of academic atmosphere in Jiangsu universities, a vice-chairman of the National Network Security and Law Enforcement Committee, and a standing director of the Computer Education Research Association of East China Universities. He has been a national famous teacher, an advanced worker in forestry system and an advanced individual in public security science and technology. Excellent teachers of the national public security system, famous teachers of teaching in Jiangsu Province, outstanding educators in Jiangsu Province, first-class individuals in Jiangsu Province, assailants in the New Long March in Jilin Province and other provincial and ministerial honorary titles; second-class and third-class achievements of the people's police were awarded twice each. He has presided over and completed eight teaching and research projects at the provincial and ministerial levels (one of which has reached the international leading level) and two research projects at the Department level; won two second-class awards for teaching results in Jiangsu Province, one teaching achievement award of the Ministry of Public Security (ranked 3), one excellent course in Jiangsu Province, one excellent course in Jiangsu Province, one excellent textbook in Jiangsu Province and one key textbook in Jiangsu Province; and he has won two second-class awards for teaching achievements in Jiangsu Province, one for Teaching Achievements Award of the Ministry He is the leader of the excellent teaching team in Jiangsu Province and the host of the construction project of Jiangsu Practical Education Center. He has won 4 copyrights of national software, 16 books and textbooks, published more than 60 papers and $12 \mathrm{EI}$ searches. His research direction is network security. 